\title{
Evaluation of photographs supporting an FFQ developed for adolescents
}

\author{
Alessandra Page Brito ${ }^{1}$, Celso Pereira Guimarães ${ }^{2}$ and Rosangela Alves Pereira ${ }^{1, *}$ \\ 'Departamento de Nutrição Social e Aplicada, Universidade Federal do Rio de Janeiro, Av. Carlos Chagas \\ Filho 373, Edifício do Centro de Ciências da Saúde, Bloco J, $2^{\circ}$ andar, Rio de Janeiro, RJ 21941-902, Brazil: \\ ${ }^{2}$ Departamento de Comunicação Visual, Universidade Federal do Rio de Janeiro, Rio de Janeiro, R, Brazil
}

Submitted 23 January 2012: Final revision received 22 June 2012: Accepted 28 September 2012: First published online 20 November 2012

\begin{abstract}
Objective: To evaluate the validity of food photographs used to support the reporting of food intake with an FFQ designed for adolescents from Rio de Janeiro, Brazil.

Design: A set of ninety-five food photographs was elaborated. The photographs' evaluation process included the acknowledgement of foods and portions in the pictures. In the identification of foods (ninety-five photographs) and typical portions (twelve photographs), the adolescents were requested to answer a structured questionnaire related to the food photographs. The identification of the portion size of amorphous foods (forty-three photographs) was performed using three different portion sizes of actual preparations. The proportions (and $95 \%$ confidence intervals) of adolescents who correctly identified foods and portion size in each photograph were estimated.

Setting: A public school in Niterói, Rio de Janeiro State, Brazil.

Subjects: Sixty-two adolescents between 11.0 and 18.9 years old, randomly selected. Results: At least $90 \%$ of adolescents correctly identified the food in ninety-two photographs and the food in the three remaining photographs was recognized by $80-89 \%$ of the adolescents. At least $98 \%$ of the adolescents correctly identified eleven typical or natural portions in the food photographs. For amorphous foods, at least $70 \%$ of teenagers correctly identified the portion size in the photograph of thirty-one foods; for the other photographs, the portion size was correctly recognized by $50-69 \%$ of the adolescents for eight foods and by less than $50 \%$ of adolescents for four foods.

Conclusions: The analysed photographs are appropriate visual aids to the reporting of food consumption by adolescents.
\end{abstract}

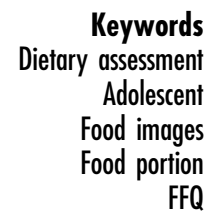

FFQ
The FFQ is a dietary intake assessment tool frequently used in epidemiological studies, as it enables categorization of individuals according to their food or energy and nutrient intake levels and estimation of the association between dietary factors and disease occurrence. Nevertheless this method shows limitations that can compromise its validity, such as the low level of accuracy in the estimation of portion size consumed ${ }^{(1)}$. Several alternatives have been applied to overcome this limitation of the FFQ, such as the use of food models and images to help individuals to report the amounts of food consumed ${ }^{(2-5)}$.

Food photographs are a low-cost option and they can be easily reproduced, transported and adapted to different working conditions ${ }^{(6)}$. The validity of photographs used in food intake assessment has been assessed among adolescents with acceptable results ${ }^{(7-11)}$.

In Brazil, food images have been used with the purpose of improving portion size estimates in food surveys ${ }^{(12-14)}$ and a study investigating the ability of adults to estimate food portions in photographs by comparing them with real foods obtained satisfactory results ${ }^{(15)}$. Nevertheless, there are no studies carried out with Brazilian adolescents that assess the validity of food images used to support dietary intake assessment. The present study aimed to evaluate food photographs supporting an FFQ designed for adolescents living in the metropolitan area of Rio de Janeiro, Brazil.

\section{Methods}

\section{Study design and population}

The study design included the identification of foods and portion sizes in a set of food photographs elaborated to support an FFQ designed for adolescents of Rio de Janeiro, Brazil. First, in order to acknowledge the foods depicted in 
ninety-five photographs and the natural portions in twelve food photographs, the adolescents were requested to answer a structured questionnaire associated with the pictures. Additionally, to evaluate the ability to identify the portion size displayed in photographs of forty-three amorphous foods, three different portion sizes of actual foods and dishes were prepared that corresponded with the photographs and shown to the adolescents. Then, the participants were asked to point out among the actual food portions which one was depicted in the photograph. Adolescents' weight and height were measured. Data were collected between 2008 and 2009. Interviewers were nutritionists and nutrition undergraduate students who were specifically trained for this purpose.

Considering a recommendation of including at least twenty-five individuals of each sex in studies designed to validate food images ${ }^{(16)}$ and anticipating a non-response rate of $40 \%$, a sex- and age-balanced sample of seventytwo adolescents was randomly selected among students of a public school in the city of Niterói, Rio de Janeiro State, Brazil. To select the participants, a list of all students between 11 and 18 years old categorized according to gender and age was elaborated. From this list, thirty-six boys and thirty-six girls were drawn randomly, being thirty-six between 11 and 14 years of age and thirty-six between 15 and 18 years of age.

The present study was approved by the Research Ethics Committee from the Institute de Medicina Social, Universidade do Estado do Rio de Janeiro, in 2005. Participation in the research was dependent on the Informed Consent Form being signed by the responsible adult or individual aged 18 years or older.

\section{FFQ design}

A detailed description of the FFQ design is published elsewhere $^{(17)}$. Briefly, the FFQ was designed according to data obtained from the $3 \mathrm{~d}$ food records of 430 adolescents aged between 12 and 18 years who were students in public schools in the city of Niterói, Rio de Janeiro State, Brazil. A total of 308 food items were mentioned in the records analysed, of which 250 were mentioned at least fifteen times and included in the FFQ, comprising an initial list of ninety items. Some of these items were composed by the assembling of similar foods; for instance, fried, roasted or stewed beef were combined in the item 'beef'. Additionally, the methodology proposed by Block et al. ${ }^{(18)}$ was applied to corroborate the consistency of the food list established for the FFQ. To achieve this, the percentage contribution of each food to the intake of energy, macronutrients, cholesterol, vitamins $\mathrm{A}$ and $\mathrm{C}, \mathrm{Fe}$ and $\mathrm{Ca}$ was estimated. It was observed that $95 \%$ of the energy and nutrient intake was provided by the foods already included in the FFQ. Five food items mentioned less than fifteen times in the records remained in the FFQ - canned fish, beer, wine, distilled beverages and low-calorie sodas - because it was believed that they can discriminate food intake or point out trends in food habits. The food portion sizes that were most frequently reported in the records were considered to determine the reference portion size for items such as rice, beans, meats and vegetables. 'Natural' or 'typical portions' were used for items like oranges and tangerines, bananas, French bread, eggs, hot dogs, crackers and cookies ${ }^{(17)}$.

The reproducibility and validity of the FFQ were assessed before photographs were included. Reliability was acceptable and relative validity was moderate to estimate the intakes of foods, energy and nutrients of adolescents in the metropolitan area of Rio de Janeiro ${ }^{(2,19)}$. These analyses indicated that the food list should be reviewed; so four items were excluded - processed soups, ketchup sauce, other processed sauces and heavy cream - and nine foods were included - grated cheese, açaí, guaraná syrup beverage, potato salad, soup, sweet potato, beef stroganoff, meat stew with vegetables, and toasts. At the end, ninety-three items comprised the FFQ list.

\section{Food photograph design}

All food items included in the FFQ developed for adolescents from the metropolitan area of Rio de Janeiro were photographed. The food photographs were developed by the Laboratório Design e Comunicação, Escola de Belas Artes, Universidade Federal do Rio de Janeiro (Design and Communication Lab, School of Fine Arts, Federal University of Rio de Janeiro). Nutritionists were responsible for the acquisition, preparation and portioning of the items photographed. The following issues were observed in the photographs' design: neutral background, lighting giving a soft contrast, focal point accuracy, perspective correction and a reference scale. The camera used was a digital Canon EOS Rebel XT with EFS 18-55 mm lens (Lake Success, NY, USA) mounted on a tripod. Foods and beverages were always photographed from the same angle and distance, using a light grey background and adopting a dinner fork and knife as reference, according to the recommendations by Nelson and Haraldsdóttir ${ }^{(20)}$.

\section{Identification of foods and typical or natural portions in photographs}

Students were exposed to ninety-five photographs of foods listed in the FFQ, so that their ability to identify the foods shown in the images could be assessed. Photographs were associated with a questionnaire including objective questions. For each photograph there was a multiple-choice question with three options naming similar foods and the students were asked to indicate the alternative that correctly described the item displayed in the image (see example in Fig. 1). For items with natural or typical portions (crackers, for instance), students were also asked to describe the amounts shown in the photographs.

\section{Identification of portion size in photographs}

Sets of three different actual portions were shown alongside photographs of forty-three amorphous foods to 


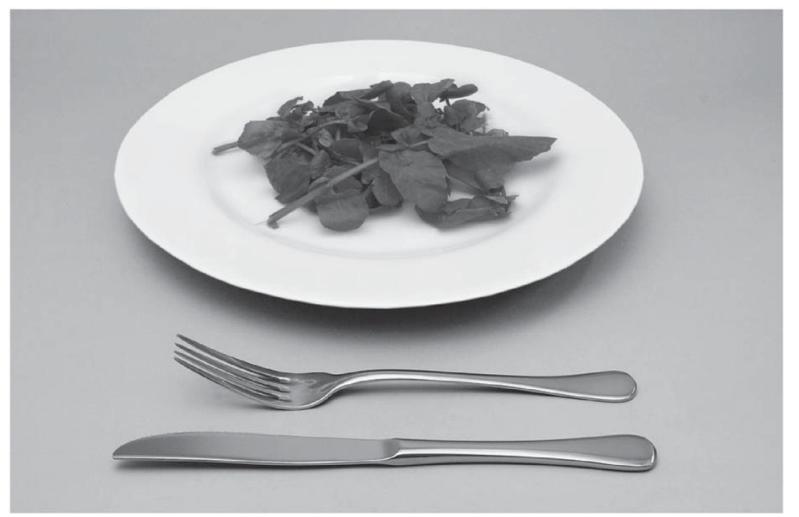

Mark with an $(X)$ the name of the food that appears in the photograph: ( ) Lettuce

( ) Watercress

( ) Cabbage

Fig. 1 Example of a question applied in the evaluation of food photographs designed to support an FFQ elaborated for adolescents

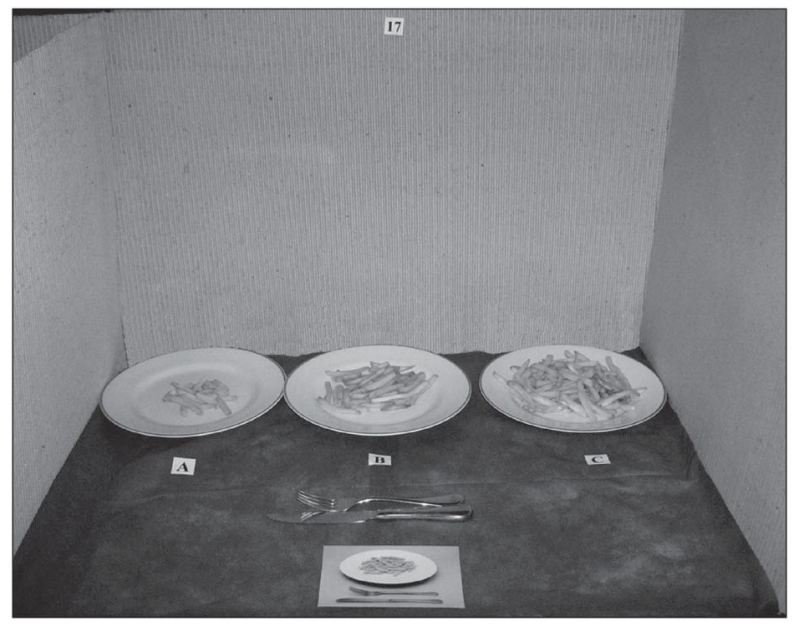

Fig. 2 Example of the display used to evaluate the recognition of portions in food photographs designed to support an FFQ elaborated for adolescents

evaluate the ability of students to identify the portion sizes in these photographs. The actual portions were displayed on the same plates and with the same silverware used in the photographs, on tables covered with fabric of the same colour used in the background of photographs. The portions were labelled as A, B and C and in each set, only one portion was the same size as that shown in the photograph; also, the different portion sizes were randomly arranged, so there was no pattern in the correct answers. In addition, each set was visualized separately (Fig. 2). Using a specific form, participants were asked to identify which actual portion was identical to the portion size displayed in the corresponding picture.

\section{Weight status assessment}

Weight status was evaluated based on BMI $(\mathrm{BMI}=$ weight $/$ height $^{2}$ ). Weight was measured with a digital scale with $150 \mathrm{~kg}$ capacity and $100 \mathrm{~g}$ variation (Plenna Sport, São Paulo, SP, Brazil). Height was measured in duplicate using a portable stadiometer with $0 \cdot 1 \mathrm{~cm}$ variation (Alturaexata, Belo Horizonte, MG, Brazil), admitting a maximum variation of $0.5 \mathrm{~cm}$ between both measures and using the mean between two measurements. Adolescents remained barefoot, wore light clothing and were in orthostatic position ${ }^{(21)}$. Weight status was classified according to the BMI-for-age-and-sex percentile, following the criteria recommended by the $\mathrm{WHO}^{(22)}$.

\section{Statistical analysis}

The proportion (and 95\% confidence interval) of correct identification of food and portion size in each photograph was calculated. The differences in the correct identification of foods and portion sizes in photographs were estimated according to sex, age group (11-14 years; $15-18$ years) and weight status (overweight; not overweight).

\section{Results}

Of the seventy-two adolescents selected, fifty-eight (81\%) participated in the identification of foods and natural or typical portions in the photographs and sixty-two (86\%) participated in identification of the portion sizes of amorphous foods in the photographs.

The adolescents who participated in the identification of foods and natural or typical portions in the photographs ( $n 58)$ had a mean age of 14.5 (SD $1 \cdot 6$ ) years; $48 \%$ were aged $11-14$ years, $48 \%$ were boys and $21 \%$ were overweight.

All fifty-eight adolescents correctly identified sixtyseven (71\%) of the ninety-five foods in the photographs. For the other photographs, between $90 \%$ and $99 \%$ of the adolescents correctly identified twenty-five foods, and between $80 \%$ and $89 \%$ of the adolescents accurately identified three foods (broccoli, chicken and powdered nutritional supplement; Table 1). There were no statistically significant differences in the identification of foods in the photographs according to sex and weight status (data not shown). However, there was a statistically significant difference between age groups, as the proportion of adolescents who correctly identified all foods was higher in adolescents aged 15-18 years compared with those aged $11-14$ years $\left(22 \% v .9 \% ; \chi^{2}\right.$ test: $\left.P=0 \cdot 02\right)$.

Of the twelve photographs showing foods in typical or natural portions, ten (lettuce, cookies, filled cookies, crackers, salty snacks, wafer, chicken nuggets, bun, cheese rolls, and toast) were accurately identified by all fifty-eight adolescents (95\% CI 94, 100\%, for all estimates). The portion of strawberries was correctly identified by $98 \%(95 \% \mathrm{CI}$ 91, 100\%) of the adolescents and the apple size (medium) was identified by $81 \%$ of them ( $95 \%$ CI $69,90 \%$ ). There were no statistically significant differences in the identification of the number of natural or typical portions in the food 
Table 1 Proportion (and 95\% confidence interval) of accurate recognition of foods in food photographs by adolescents ( $n 58)$, Niterói, Rio de Janeiro State, Brazil, 2008-2009

\begin{tabular}{|c|c|c|c|}
\hline \multirow[b]{2}{*}{ Food } & \multirow{2}{*}{$\begin{array}{c}\text { Accurate } \\
\text { recognition (\%) }\end{array}$} & \multicolumn{2}{|c|}{$95 \% \mathrm{Cl}$} \\
\hline & & Lower & Upper \\
\hline Cassava & 98 & 91 & 100 \\
\hline Cake with filling & 98 & 91 & 100 \\
\hline Liver & 98 & 91 & 100 \\
\hline Jelly & 98 & 91 & 100 \\
\hline Bologna & 98 & 91 & 100 \\
\hline Nuggets & 98 & 91 & 100 \\
\hline Cheese rolls & 98 & 91 & 100 \\
\hline Cabbage & 98 & 91 & 100 \\
\hline Potato salad & 98 & 91 & 100 \\
\hline Soup & 98 & 91 & 100 \\
\hline Pumpkin & 97 & 88 & 100 \\
\hline Watercress & 97 & 88 & 100 \\
\hline Cake & 97 & 88 & 100 \\
\hline Stroganoff & 97 & 88 & 100 \\
\hline Yoghurt & 97 & 88 & 100 \\
\hline Milk & 97 & 88 & 100 \\
\hline Porridge & 97 & 88 & 100 \\
\hline $\mathrm{Ham}$ & 97 & 88 & 100 \\
\hline Corn flakes & 97 & 88 & 100 \\
\hline Toast & 97 & 88 & 100 \\
\hline Cauliflower & 95 & 86 & 99 \\
\hline Fish & 95 & 86 & 99 \\
\hline Chocolate powder & 93 & 83 & 98 \\
\hline Beef stew with vegetables & 93 & 83 & 98 \\
\hline Chicken breast & 91 & 81 & 97 \\
\hline Broccoli & 90 & 79 & 96 \\
\hline Nutritional supplement & 86 & 75 & 94 \\
\hline Chicken & 81 & 69 & 90 \\
\hline
\end{tabular}

photographs according to sex, weight status and age group (data not shown).

The adolescents who participated in the identification of portion size of amorphous foods ( $n$ 62) had a mean age of 14.4 (SD 1.9) years; $55 \%$ were aged $11-14$ years, $47 \%$ were boys and $21 \%$ were overweight. At least $80 \%$ of adolescents correctly identified the portion size in twenty-one (49\%) of forty-three food photographs selected for the portion recognition study. Seventeen food portion sizes in the photographs were correctly identified by between $60 \%$ and $79 \%$ of adolescents; four were accurately identified by between $40 \%$ and $59 \%$ of adolescents; and the portion size of tomatoes was correctly identified by $29 \%$ of adolescents (Table 2). There were no statistically significant differences in the number of portion sizes correctly identified in the photographs according to sex, weight status and age group (data not shown).

\section{Discussion}

Brazilian adolescents in the present study satisfactorily identified foods and their portions from photographs: about $80 \%$ of these foods were correctly recognized from the photographs by all adolescents, $83 \%$ of the natural and typical portions shown in the photographs were correctly identified by all participants, and $89 \%$ of the
Table 2 Proportion (and 95\% confidence interval) of accurate recognition of portion size in photographs of amorphous foods by adolescents ( $n$ 62), Niterói, Rio de Janeiro State, Brazil, 2008-2009

\begin{tabular}{|c|c|c|c|}
\hline \multirow[b]{2}{*}{ Food } & \multirow{2}{*}{$\begin{array}{c}\text { Accurate } \\
\text { recognition (\%) }\end{array}$} & \multicolumn{2}{|c|}{$95 \% \mathrm{Cl}$} \\
\hline & & Lower & Upper \\
\hline French fries & 98 & 92 & 100 \\
\hline Pumpkin & 96 & 88 & 100 \\
\hline Polenta* & 95 & 87 & 99 \\
\hline Chicken pie & 95 & 87 & 99 \\
\hline Gnocchi & 95 & 87 & 99 \\
\hline Potato salad & 94 & 85 & 98 \\
\hline Farofat & 92 & 83 & 97 \\
\hline Milk & 92 & 83 & 97 \\
\hline Cassava & 91 & 81 & 96 \\
\hline Beef & 91 & 81 & 96 \\
\hline Rice & 89 & 79 & 96 \\
\hline Pasta & 89 & 79 & 96 \\
\hline Canned fish & 87 & 76 & 95 \\
\hline Coffee & 87 & 76 & 95 \\
\hline Cucumber & 86 & 73 & 94 \\
\hline Corn flakes & 85 & 74 & 92 \\
\hline Cabbage & 85 & 74 & 92 \\
\hline Sausage & 84 & 71 & 92 \\
\hline Papaya & 84 & 71 & 92 \\
\hline Pork ribs & 82 & 70 & 90 \\
\hline Stroganoff & 82 & 70 & 90 \\
\hline Guava & 80 & 66 & 89 \\
\hline Cake & 78 & 65 & 88 \\
\hline Boiled potato & 78 & 65 & 88 \\
\hline Cream of wheat & 77 & 64 & 87 \\
\hline Beans & 77 & 64 & 87 \\
\hline Lasagne & 75 & 63 & 85 \\
\hline Cream cheese & 75 & 63 & 85 \\
\hline Ground meat & 74 & 62 & 84 \\
\hline Grated carrot & 74 & 62 & 84 \\
\hline Fish & 74 & 62 & 84 \\
\hline Yam & 69 & 56 & 80 \\
\hline Watercress & 68 & 55 & 79 \\
\hline Margarine & 67 & 53 & 78 \\
\hline Pudding & 66 & 53 & 77 \\
\hline Guava jam & 63 & 50 & 75 \\
\hline Liver & 61 & 47 & 74 \\
\hline Beef stew with vegetables & 60 & 46 & 72 \\
\hline Chicken & 52 & 38 & 65 \\
\hline Pineapple & 47 & 34 & 61 \\
\hline Porridge & 43 & 31 & 57 \\
\hline Chocolate powder & 40 & 28 & 53 \\
\hline Tomato & 29 & 18 & 43 \\
\hline
\end{tabular}

*Polenta is a typical Brazilian dish made of cornmeal boiled in water with salt.

tFarofa is a typical Brazilian dish made of toasted cassava flour, usually mixed with salt and spices.

amorphous food portion sizes shown in the photographs were identified by at least $60 \%$ of participants. There were no statistically significant differences in the identification of portions according to sex, age group and weight status.

Comparing the results with other studies validating food photographs is not simple due to variability in the foods analysed and differences in the methods applied. Turconi et al. ${ }^{(23)}$ assessed the validity of food photographs in the estimation of food intake by children, adolescents and adults and also observed that there were no statistically significant differences in the identification of portion size in food photographs according to sex, age 
and weight status. Lillegaard et $a l^{(9)}$ and Frobisher and Maxwell $^{(11)}$ also found that there were no statistically significant differences in the identification of portion size in food photographs according to age.

In the present study, the adolescents' ability to identify food portion size in the photographs was independent of food characteristics, as the identification of food portions in the photographs was similar for foods with natural portions and for amorphous foods. Venter et $a l^{(24)}$ developed food photographs to help adult individuals to describe the portions consumed in a cross-sectional study conducted in Africa. These authors observed that portion sizes of solid foods were more accurately estimated from photographs than those of amorphous foods such as porridge, beans, rice and pumpkin.

Vereecken et $a l .{ }^{(7)}$ conducted a study in Belgium to evaluate the precision in estimating the portion size of amorphous foods in photographs among adolescents. The convenience sample was composed of 128 adolescents, $58 \%$ male, aged between 11 and 17 years. The authors observed that, on average, $28 \%$ of the adolescents accurately recognized amorphous food portion sizes in photographs, a proportion lower than that observed in the present study (77\%). However, Vereecken et al. ${ }^{(7)}$ provided nine or more photographs for each food item, while in the present study one food photograph was compared with three different portions of real food.

Lillegaard et $a l^{(9)}$ also investigated if children and adolescents could accurately estimate food portion size based on food pictures. The authors found that, on average, $60 \%$ of sixty-three adolescents aged 9-19 years appropriately recognized the food portions in photographs. Lillegaard et al. ${ }^{(9)}$ observed results similar to those in the present study for potato chips and rice. On the other hand, those authors observed a lower rate of precise recognition for fat spread on bread and fish than obtained in our study; while the proportion of correct identification in the images of spaghetti with tomato sauce and porridge observed by Lillegaard et $a l^{(9)}$ was higher than that found in the present analysis.

In Brazil, food photographs have been used to assist the estimation of the amount of food intake $e^{(12-14)}$. However, only Lopez and Botelho(15) investigated the ability of 120 adults to estimate food portion size in thirty-one photographs displaying foods in small, medium and large portions by comparing them with real foods. These authors obtained less positive results than those observed in the present study for pumpkin, French fries, ground meat, grated carrot, corn flakes, pasta, farofa (a typical Brazilian dish made of toasted cassava flour, usually mixed with salt and spices), beans and papaya. Results for rice and milk were similar in both studies, and the portion sizes of chicken breast, tomato and cake were more successfully identified in the study of Lopes and Botelho ${ }^{(15)}$.

The present study sought to reduce the possibility of bias when evaluating food photographs: participants received detailed instructions about the procedures applied in data collection, which was carried out individually in a quiet environment. Also, since Lillegaard et $a l .{ }^{(9)}$ pointed out that the proportion of accurate recognition was higher for foods that had precisely the same appearance shown in the pictures, we were careful in arranging the actual portions that were compared with the photographs. To prevent differences between the appearance of real foods and those in photographs, preparations were cooked on the day of data collection and the portions were arranged in the dishes identically as they were in photographs. Additionally, plates, forks and knives were the same as used in the pictures.

The lowest frequencies of correct identification of portion size were observed for apple and tomato, probably due to the fact that these pictures, although including a fork and a knife as a size reference, did not enable an average apple or tomato to be distinguished without a large and a small apple or tomato as reference.

The studied sample size met the recommendation of Nelson and Haraldsdóttir ${ }^{(16)}$ regarding the number of participants in studies on the validation of food images. Additionally, the photographs were designed according to the advice of experts in this subject ${ }^{(20)}$. Moreover, the serving sizes adopted were derived from the food intake survey conducted among adolescents from the same region, and therefore were appropriate for the target group. According to Foster et $a l .^{(25)}$, the appropriateness of foods serving sizes enables more accurate reporting of food portions consumed.

The present study is a novel one conducted in Brazilian adolescents and the photographs analysed are appropriate to assist the obtainment of data in studies on food intake applying the FFQ developed for adolescents. These tools will be useful in the assessment and monitoring of food intake of adolescents in Brazil, which is central to establish health and nutrition policies and programmes targeting adolescents, as this group is particularly vulnerable to changes in food habits.

\section{Acknowledgements}

Sources of funding: This work received financial support from the Brazilian National Scientific and Technological Research Council (506336/2004-2). Conflicts of interest: The authors declare no conflict of interest. Authors' contributions: A.P.B. participated in the photograph elaboration, data collection, analysis and interpretation, manuscript drafting and final editing. C.P.G. was responsible for the photograph elaboration, study design and data interpretation. R.A.P. was responsible for the research conception and supervision, data analysis and interpretation, manuscript conception, writing and final editing. Acknowledgements: The authors acknowledge the work of Marco Cadena, Carolina Cadaval, Barbara Carreira and Juliana Carneiro Novaes from the School of Fine Arts, 
Federal University of Rio de Janeiro in the design and technical treatment of the photographs. The authors are also grateful to the Professor Ronir Raggio Luiz, from the Institute of Studies on Collective Health, Federal University of Rio de Janeiro, for his guidance in the statistical analysis.

\section{References}

1. Cade J, Thompson R, Burley V et al. (2002) Development, validation and utilization of food-frequency questionnaires a review. Public Health Nutr 5, 567-587.

2. Araujo MC, Yokoo EM \& Pereira RA (2010) Validation and calibration of a semiquantitative food frequency questionnaire designed for adolescents. J Am Diet Assoc 110, 1170-1177.

3. Ngo J, Engelen A, Molag M et al. (2009) A review of the use of information and communication technologies for dietary assessment. Br J Nutr 101, Suppl. 2, S102-S112.

4. Navarro A, Cristaldo PE, Díaz MP et al. (2000) Food photography atlas: its suitability for quantifying food and nutrient consumption in nutritional epidemiological research in Córdoba, Argentina. Rev Fac Cien Med Univ Nac Cordoba 57, 67-74.

5. Haraldsdóttir J, Tjønneland A \& Overvad K (1994) Validity of individual portion size estimates in a food frequency questionnaire. Int J Epidemiol 23, 786-796.

6. Huybregts L, Roberfroid D, Lachat C et al. (2008) Validity of photographs for food portion estimation in a rural West African setting. Public Health Nutr 11, 581-587.

7. Vereecken C, Dohogne S, Covents M et al. (2010) How accurate are adolescents in portion-size estimation using the computer tool Young Adolescents' Nutrition Assessment on Computer (YANA-C)? Br J Nutr 103, 1844-1850.

8. Higgins JA, LaSalle AL, Zhaoxing P et al. (2009) Validation of photographic food records in children: are pictures really worth a thousand words? Eur J Clin Nutr 63, 1025-1033.

9. Lillegaard IT, Overby NC \& Andersen LF (2005) Can children and adolescents use photographs of food to estimate portion sizes? Eur J Clin Nutr 59, 611-617.

10. Beasley LJ, Hackett AF, Maxwell SM et al. (2004) The effect of a dietary preload on estimation of usual food portion size by photograph in female volunteers. J Hum Nutr Diet 17, 219-225.

11. Frobisher C \& Maxwell SM (2003) The estimation of food portion sizes: a comparison between using descriptions of portion sizes and a photographic food atlas by children and adults. J Hum Nutr Diet 16, 181-188.
12. Zabotto CB, Vianna RPT \& Gil MF (1996) Registro Fotográfico para Inquéritos Dietéticos. Goiânia: RTN.

13. Sales RL, Silva MMS \& Costa NMB (2004) Avaliando o consumo alimentar por fotos (software). Viçosa: Federal University of Viçosa.

14. Monteiro JP, Pfrimer K, Tremeschin MH et al. (2007) Consumo Alimentar: Visualizando Porções. Rio de Janeiro: Editora Guanabara Koogan.

15. Lopez RPS \& Botelho RBA (2010) Identificação de porções alimentares em fotografias. Rev Soc Bras Alim Nutr 35, $1-14$.

16. Nelson M \& Haraldsdóttir J (1998) Food photographs: practical guidelines I. Design and analysis of studies to validate portion size estimates. Public Health Nutr 1, 219-230.

17. Araujo MC, Veiga GV, Sichieri R et al. (2010) Elaboração de questionário semiquantitativo de freqüência alimentar para adolescentes da Região Metropolitana do Rio de Janeiro, Brasil. Rev Nutr 23, 179-189.

18. Block G, Hartman AM, Dresser CM et al. (1986) A databased approach to diet questionnaire design and testing. Am J Epidemiol 124, 453-469.

19. Araujo MC, Ferreira DM \& Pereira RA (2008) Reprodutibilidade de questionário semiquantitativo de freqüência de consumo de alimentos elaborado para adolescentes da região metropolitana do Rio de Janeiro, Brasil. Cad Saude Publica 24, 2775-2786.

20. Nelson M \& Haraldsdóttir J (1998) Food photographs: practical guidelines II. Development and use of photographic atlases for assessing food portion size. Public Health Nutr 1, 231-237.

21. Gordon CC, Chumlea WC and Roche AF (1988) Stature, recumbent length, and weight. In Anthropometric Standardization Reference Manual, pp. 3-8 [TG Lohman, AF Roche and R Martorell, editors]. Champaign, IL: Human Kinetics Books.

22. de Onis M, Onyango AW, Borghi E et al. (2007) Development of a WHO growth reference for school-aged children and adolescents. Bull World Health Organ 85, 660-667.

23. Turconi G, Guarcello M, Gigli Berzolari F et al. (2005) Valuation of a colour food photography atlas as a tool for quantifying food portion size in epidemiological dietary surveys. Eur J Clin Nutr 59, 923-931.

24. Venter CS, Macintyre UE \& Vorster HH (2000) The development and testing of a food portion photograph book for use in an African population. J Hum Nutr Diet 13, 205-218.

25. Foster E, Matthews JNS, Nelson M et al. (2006) Accuracy of estimates of food portion size using food photographs the importance of using age-appropriate tools. Public Health Nutr 9, 509-514. 